$4-2019$

\title{
The use of folic acid in dengue: Has it any value?
}

Asif Ali Shah

Aga Khan University

Ahsan Ali Syed

Aga Khan University, syed.ahsan@aku.edu

Saad Bin Zafar

Aga Khan University

Safia Awan

Aga Khan University, safia.awan@aku.edu

Follow this and additional works at: https://ecommons.aku.edu/pakistan_fhs_mc_med_intern_med

Part of the Internal Medicine Commons

\section{Recommended Citation}

Shah, A. A., Syed, A. A., Zafar, S. B., Awan, S. (2019). The use of folic acid in dengue: Has it any value?.

Tropical Doctor, 49(2), 85-87.

Available at: https://ecommons.aku.edu/pakistan_fhs_mc_med_intern_med/129 


\section{The use of folic acid in dengue: has it any value?}

Folic acid in dengue

Syed Ahsan Ali ${ }^{1}$

Saad Bin Zafar

Asif Ali Shah ${ }^{1}$

Safia Awan ${ }^{1}$

1. Department of Medicine

The Aga Khan University Hospital, Karachi

Pakistan

Corresponding Author:

Syed Ahsan Ali

Assistant Professor,

Department of Medicine

The Aga Khan University Hospital, Karachi. Pakistan

Address: First Floor, Faculty Office Building. The Aga Khan University Hospital. Stadium Road, Karachi. Pakistan. 74800.

Email: syed.ahsan@aku.edu

Key Words: Dengue; Folic acid; Thrombocytopenia

Declaration of conflicting interests

The authors declared no potential conflicts of interest with respect to the research, authorship, and publication of this article.

\section{Abstract}

Folic acid is used in dengue patients. Our study aims to compare the duration of recovery of thrombocytopenia in patients with dengue infection who received folic acid and those who did not. We retrospectively reviewed the medical records of adult patients admitted over six years with a diagnosis of dengue. Of 2,216 patients, 1464 fulfilled the inclusion criteria. Group A were those patients who received folic acid and group B were those who 
did not. 1322 (90.3\%) patients received folic acid. Mean time period required for platelets to double the nadir was 1.7 ( \pm 2.2 ) days days in both groups $A$ and $B$ ( $p$ value 0.89 ). In conclusion, there is no significant difference in the recovery of thrombocytopenia in patients with dengue fever who received folic and those who did not receive folic acid.

\section{Introduction}

South Asia has been declared as an endemic area of dengue infection by the World Health Organization (WHO). Pakistan has been hit by several dengue epidemics since 1994 and now is an endemic area.(1) Despite being a growing threat to almost whole world there is still no specific treatment for dengue infection, and treatment largely remains supportive. Several specific treatments have been tried in patients with no robust data to suggest any therapeutic options as standard. Such include steroids, ${ }^{(2)}$ calcium and vitamin D supplements, (3) papaya leaves extract, (4) chloroquine, (5)immunoglobulin, (6) folic acid ${ }^{(7,8)}$ and so on. Many of these treatment regimens focus on rapid improvement of thrombocytopenia.

Folic acid is frequently used without any scientific basis. (7) Up to $30 \%$ of paediatric patients with dengue infection received folic acid in addition to other supportive measures in a typical Indian study. ${ }^{(8)}$ The rationale for folic acid use in dengue is not clear. It may be prescribed because of its low cost, its few adverse effects and its role as a haematinic. Interestingly, one study (9) showed that the replication of dengue viruses inhibited by methotrexate was restored by folinic acid, a natural folate. Hence it is possible that folic acid may actually be deleterious in dengue!

\section{Materials and methods}

This study was conducted at the Department of Medicine of the Aga Khan University Hospital Karachi, Pakistan, which is a 700 bed tertiary care academic medical institute 
receiving patients not only from Karachi, which is the most populous city of Pakistan with an estimated population in excess of 20 million, but also from rest of the country. Ethical approval was obtained for the study from the institutional Ethical Review Committee (4095-Med-ERC-16).

Our primary objective was to determine the duration of recovery of thrombocytopenia in patients with dengue infection who received and did not receive folic acid during hospitalization. The secondary objectives were to compare the mortality, ICU stay, length of stay, and creatinine among patients with dengue infection between the two groups. We reviewed the medical records of all patients over 16 years of age admitted in the department of Medicine at our hospital from 1st June 2007 to 31 ${ }^{\text {st }}$ December 2013 with a diagnosis of dengue infection who had evidence of doubling of platelets from an earlier nadir. All patients who had received platelet transfusion were excluded from the study. A case of dengue fever was defined as a patient admitted with fever who had a positive dengue IgM antibody or dengue antigen test. The lowest platelet count after admission was recorded. Subsequent platelet counts double the nadir were also recorded during the hospital stay, as were creatinine levels at the time of admission and discharge, and the length of hospital stay. Group A were those patients who received folic acid and group B were those who did not.

Data regarding frequency of deaths and ICU stay were also collected and compared between the two groups and compared. P values $<0.05$ were deemed significant. Fisher's exact T test and Mann-Whitney $U$ test were used to compute $P$ values. All analyses were conducted by using the Statistical Package for Social Science SPSS 19.0 (IBM Corp. Released 2010. IBM SPSS Statistics for Windows, Version 19.0. Armonk, NY: IBM Corp.).

\section{Results}


Medical records of 2,216 adult patients who were admitted in our hospital with a diagnosis of dengue infection from 1st June 2007 to 31stDecember 2013 were analysed. 1464 fulfilled our inclusion criteria. Their mean age was $36.6( \pm 15.0)$ years. The mean lowest platelet count was $35.5( \pm 13.2) \times 10 \% /$ L. The mean doubled platelet count from nadir was $81.3( \pm 35.2) \times 10 \% / \mathrm{L}$. The dose of folic acid received by each patient was $5 \mathrm{mg}$ per day (Table 1).

Out of the 1464 patients, 1322 (90.3\%) received folic acid. The mean time period required for platelets to double the nadir was 1.7 ( \pm 2.2$)$ days and $1.7( \pm 2.2)$ days, respectively, in groups $A$ and $B(P=0.89)$ (Table 2). Only 11 patients required ICU admission and all of them belonged to group A ( $P=0.99)$. Similarly, there were only two patients who died and both were of group $A(P=0.99)$.

The mean creatinine at admission was $107.9( \pm 31.7)$ and $105( \pm 31.1) \mu \mathrm{mol} / \mathrm{L}$ in group $A$ and B respectively $(P=0.30)$, and at discharge $107( \pm 31.5) \mu \mathrm{mol} / \mathrm{L}$ and $105.9( \pm$ 35) $\mu \mathrm{mol} / \mathrm{L}$, respectively $(P=0.69)$.

Data extracted are shown in Tables $1 \& 2$. 
Table 1. Baseline characteristics of study population $(n=1464)$

\begin{tabular}{|l|l|}
\hline & \\
\hline Mean age & $36.5 \pm 15.0$ years \\
\hline Mean lowest platelet count & $35.5 \pm 13.2 \times 10 \% / \mathrm{L}$ \\
\hline Mean doubled platelet count from nadir & $81.3 \pm 35.2 \times 10 \% / \mathrm{L}$ \\
\hline Mean platelet doubling time & $1.7 \pm 2.2$ days \\
\hline Dose of folic acid received by each patient & $5 \mathrm{mg}$ per day \\
\hline Mean length of hospital stay (days) & $3.4 \pm 3.9$ \\
\hline Mean creatinine at admission ( $\mu \mathrm{mol} / \mathrm{L})$ & $107.5 \pm 31.6$ \\
\hline Mean creatinine at discharge $(\mu \mathrm{mol} / \mathrm{L})$ & $106.8 \pm 31.8$ \\
\hline
\end{tabular}

Table 2. Frequency and comparison of doubling time of platelets from nadir, creatinine, length of stay, ICU admission and mortality status in group A (dengue patients who received folic acid) and B (dengue patients who did not receive folic acid) ( $n=1464)$

\begin{tabular}{|c|c|c|c|}
\hline & Group A & Group B & $p$ value \\
\hline Mean age (years) & $36.6 \pm 14.9$ & $35.9 \pm 15.4$ & 0.38 \\
\hline $\begin{array}{l}\text { Mean lowest platelet } \\
\text { count }(\times 10 \% / L)\end{array}$ & $35.7 \pm 13.3$ & $34.5 \pm 12.6$ & 0.37 \\
\hline $\begin{array}{l}\text { Mean doubled platelet } \\
\text { count from nadir ( } 10 \% / L)\end{array}$ & $81.5 \pm 35.3$ & $79.5 \pm 33.7$ & 0.52 \\
\hline $\begin{array}{l}\text { Mean Platelets doubling } \\
\text { time from nadir (days) }\end{array}$ & $1.7 \pm 2.2$ & $1.7 \pm 2.2$ & $0.89 *$ \\
\hline $\begin{array}{l}\text { Mortality } \\
\text { Yes } \\
\text { No } \\
\end{array}$ & $\begin{array}{c}2(0.15 \%) \\
1320(99.84 \%)\end{array}$ & $\begin{array}{c}0(0 \%) \\
142(100 \%)\end{array}$ & $0.99 * *$ \\
\hline $\begin{array}{l}\text { ICU admission } \\
\text { (no. of patients) } \\
\text { Yes } \\
\text { No }\end{array}$ & $\begin{array}{c}11(0.83 \%) \\
1311(99.16 \%)\end{array}$ & $\begin{array}{c}0(0 \%) \\
142(100 \%)\end{array}$ & $0.99 * *$ \\
\hline
\end{tabular}




\begin{tabular}{|l|c|c|c|}
\hline $\begin{array}{l}\text { Mean length of hospital } \\
\text { stay (days) }\end{array}$ & $3.4 \pm 3.9$ & $3.6 \pm 3.9$ & $0.75^{*}$ \\
\hline $\begin{array}{l}\text { Mean creatinine at } \\
\text { admission }(\mu \mathrm{mol} / \mathrm{L})\end{array}$ & $107.8 \pm 31.7$ & $105 \pm 31.1$ & 0.30 \\
\hline $\begin{array}{l}\text { Mean creatinine at } \\
\text { discharge }(\mu \mathrm{mol} / \mathrm{L})\end{array}$ & $107 \pm 31.5$ & $105.8 \pm 35$ & 0.69 \\
\hline
\end{tabular}

*Mann-Whitney $U$ test

**Fisher's Exact test

\section{Discussion}

Our study showed that there was no significant difference in the duration of recovery of thrombocytopenia whether folic acid was taken or not. There was likewise no significant difference in length of hospital stay.

There is no specific treatment available for dengue fever and good supportive treatment is the mainstay of management, (10) but the use of several drugs has been proposed. ${ }^{2-6)}$ Trials in vitro including anti-TNF antibodies, (11) celgosivir and ribavirin (antiviral agents), ${ }^{(12,13)}$ have been undertaken without conclusive success.

Thrombocytopenia, being the most important manifestation of dengue, has been the target of most of these studies. Use of folic acid, despite the absence of scientific justification, is virtually ubiquitous. ${ }^{(7,8)}$

\section{Conclusion}

To the best of our knowledge, ours is the first of its kind assessing the effects of folic acid supplementation on several outcomes of dengue. This study presents only retrospective data, and we compared the doubling time from a nadir value of platelets rather than absolute values as a marker of recovery of thrombocytopenia. There is a need for prospective controlled studies to compare the effects of folic acid on both the recovery of thrombocytopenia and other parameters in patients with dengue. However, it seems that there is no significant value in the use of folic acid regarding recovery of thrombocytopenia in dengue. 


\section{Funding}

This research received no specific grant from any funding agency in the public, commercial, or notfor-profit sectors.

\section{Declaration of conflicting interests}

The authors declared no potential conflicts of interest with respect to the research, authorship, and publication of this article.

\section{References}

1. Jahan F. Dengue Fever (DF) in Pakistan. Asia Pac Fam Med. 2011;10(1):1.

2. Shashidhara KC, Murthy KAS, Gowdappa HB, Bhograj A. Effect of high dose of steroid on plateletcount in acute stage of dengue fever with thrombocytopenia. Journal of clinical and diagnostic research: JCDR. 2013;7(7):1397.

3. Sanchez-Valdez E, Delgado-Aradillas M, Torres-Martinez JA, Torres-Benitez JM. Clinical response in patients with dengue fever to oral calcium plus vitamin D administration: study of 5 cases. Proc West Pharmacol Soc. 2009;52:14-7.

4. Ahmad N, Fazal H, Ayaz M, Abbasi BH, Mohammad I, Fazal L. Dengue fever treatment with Carica papaya leaves extracts. Asian Pac J Trop Biomed. 2011 Aug;1(4):330-3.

5. Tricou V, Minh NN, Van TP, et al. A randomized controlled trial of chloroquine for the treatment of dengue in Vietnamese adults. PLoS Negl Trop Dis. 2010 Aug 10;4(8):e785.

6. Dimaano EM, Saito M, Honda S, et al. Lack of efficacy of high-dose intravenous immunoglobulin treatment of severe thrombocytopenia in patients with secondary dengue virus infection. Am J Trop Med Hyg. 2007 Dec;77(6):1135-8.

7. Jayasinghe NS, Thalagala E, Wattegama M, Thirumavalavan K. Dengue fever with diffuse cerebral hemorrhages, subdural hematoma and cranial diabetes insipidus. BMC research notes.

2016;9(1):265.

8. Ghazala Z, Anuradha HV, Shivamurthy MC. Pattern of management and outcome of dengue fever in pediatric in-patients in a tertiary care hospital: a prospective observational study. International Journal of Basic \& Clinical Pharmacology. 2014;3(3):534-8. 
9. Fischer MA, Smith JL, Shum D, et al. Flaviviruses are sensitive to inhibition of thymidine synthesis pathways. J Virol. 2013 Sep;87(17):9411-9.

10. WHO. Dengue guidelines for diagnosis, treatment, prevention and control. 2009 [updated 2009; cited]; 2013/06/14:[Available from: http://www.who.int/rpc/guidelines/9789241547871/en/.

11. Atrasheuskaya A, Petzelbauer P, Fredeking TM, Ignatyev G. Anti-TNF antibody treatment reduces mortality in experimental dengue virus infection. FEMS Immunol Med Microbiol. 2003 Jan 21;35(1):33-42

12. Rathore AP, Paradkar PN, Watanabe S, et al. Celgosivir treatment misfolds dengue virus NS1 protein, induces cellular pro-survival genes and protects against lethal challenge mouse model. Antiviral Res. 2011 Dec;92(3):453-60.

13. Chang J, Schul W, Butters TD, et al. Combination of alpha-glucosidase inhibitor and ribavirin for the treatment of dengue virus infection in vitro and in vivo. Antiviral Res. 2010 Jan;89(1):26-34. 